\title{
Políticas Culturais: Contribuições para o necessário debate
}

Se a política pode ser encarada como o campo das escolhas a partir de valores, bem como a luta e o exercício pelo e do poder; se o poder pode assumir múltiplas formas e se a cultura continua a ser um conceito vivo e dinâmico, considera-se fundamental, numa altura em que a crise generalizada tem facilmente servido como álibi para o desinvestimento - político e financeiro - neste setor fundamental para a capacitação e qualificação individual e coletiva, contribuir para uma discussão que, apesar de tudo, tem estado pouco presente na academia e na sociedade civil. O poder de transformação da cultura é inquestionável, mas aspetos como o esbater de fronteiras entre os setores cultural e criativo, ou ainda os fracos níveis de articulação consistente entre os diversos sectores e níveis de decisão política, ou mesmo a pouca exploração da língua portuguesa como fator identitário para a promoção de estratégias concertadas de internacionalização, podem estar a contribuir para o desperdício de oportunidades, como a promoção de formas de crescimento inteligente, inclusivo e sustentável.

Tendo como pano de fundo as profundas transformações que atravessam as sociedades contemporâneas, a Revista Lusófona de Estudos Culturais reúne no seu $4^{0}$ número um conjunto de artigos que procuram concorrer para uma discussão crítica, construtiva e prospectiva sobre as políticas culturais públicas e privadas, locais, regionais, nacionais e transnacionais.

O debate inicia-se com o contributo de Teresa Tipton da Anglo-American University de Praga, que apresenta uma visão crítica da divisão entre os discursos para o desenvolvimento da economia do conhecimento, a sustentabilidade, a formação dos gestores culturais, bem como o seu campo de ação. A partir de relatórios recentes sobre o setor cultural e criativo e, tendo em consideração a redução dos financiamentos a que, nomeadamente em Portugal, o setor tem sido votado, a autora convoca conceitos do biólogo Jakob von Uexküll e do economista Manfred Max-Neef para, por um lado, sublinhar os benefícios que se podem retirar da instabilidade da vida contemporânea e, por outro lado, alertar para a necessidade de se repensar a formação no âmbito da gestão que deve passar a incluir, de forma mais efetiva, aspetos culturais e promover a 
criatividade. Inspirada na obra de Max-Neef e no trabalho Dag Hammarskjöld Foundation a autora considera ainda ser possível desenvolver novas estratégias que concorram para o desenvolvimento de novas políticas, que invertam os miasmas da insustentabilidade do setor cultural em Portugal.

Gil Fesch, do Instituto de Sociologia da Universidade do Porto, propõe-nos uma breve viagem sobre as políticas culturais europeias da segunda metade do século XX usando, essencialmente, o exemplo francês uma vez que, segundo o autor, este serve para ilustrar, com as óbvias distinções nacionais, os avanços e recuos que genericamente se observaram nas políticas culturais da Europa Ocidental e para tentar lançar uma luz sobre os próximos desafios para as políticas culturais contemporâneas.

O protagonismo que, em termos de discurso, o sector da cultura tem assumido, enquanto um dos eixos estratégicos do desenvolvimento económico sustentável, por um lado, e da necessidade de, por exemplo no domínio do Património Cultural, fazer acompanhar o discurso com investimentos significativos, por outro lado, são os pontos de partida para a reflexão de João Pedro Bernardes, Luís Filipe Oliveira, Ricardo Moreira e Teresa Valente da Universidade do Algarve. A análise aqui apresentada, que integra um estudo mais amplo realizado para o Gabinete de Estratégia, Planeamento e Avaliação Culturais do Governo de Portugal no âmbito do Plano de Estudos Cultura 2020, visa assinalar alguns dos aspetos relevantes que possam contribuir para que o Património Cultural se transforme num fator de diferenciação, qualificação e dinamização económica das regiões portuguesas.

A abordagem de Mirian Tavares, do Centro de Investigação em Artes e Comunicação da Universidade do Algarve, também se centra no papel que a criatividade e a cultura podem assumir no desenvolvimento regional. Para evitar os equívocos que, não raras vezes, rodeiam as denominadas Indústrias Criativas, a autora apresenta uma reflexão sobre a evolução do conceito de Indústria Cultural, criado em meados do século XX por Adorno e Horkheimer, até ao conceito atual de Indústrias Criativas, relacionando a evolução conceptual com conceitos como o de Cultura e o de Civilização, para enfatizar o papel das Artes na Economia Contemporânea.

A partir de um caso prático de uma região no sul do Brasil - Missões jesuítas-guaranis -, Marcela Guimarães Silva e Tiago Costa Martins, da Universidade Federal do Pampa no Brasil, apresentam um conjunto de evidências, resgatadas da atuação do Governo de Getúlio Vargas nos períodos em que presidiu ao país, que podem ser úteis para o debate, sempre atual, sobre as políticas culturais públicas e as práticas culturais. Fruto deste trabalho, os autores destacam aquelas que consideram ser as cinco atribuições 
fundamentais das instituições culturais do Estado - a regulação, a normatização, a cognição, a gestão e a mediação - e que podem contribuir para uma melhor compreensão da relação entre as práticas culturais e as políticas culturais.

Compreender a relação entre as práticas culturais de um grupo de alunos do ensino superior, os equipamentos culturais da região e a instituição de ensino superior que frequentam, é a proposta que nos apresentam Erick Nimrichter, Hayla Thami Lage e Natália Cabral Muniz, do Instituto Federal do Rio de Janeiro (Campus São Gonçalo). A particularidade deste trabalho prende-se com o facto de se tratar de um projeto em curso o que permitirá, no futuro, verificar se as propostas apresentadas de alargamento do estudo a outras regiões se concretizaram e se alguma alteração ao cenário agora encontrado se produzirá. As conclusões provisórias do estudo salientam, mais uma vez, o pouco investimento no setor cultural o que, no caso específico e em efeito dominó, tem consequências na escassez da oferta, condiciona as práticas culturais dos alunos e impele a instituição de ensino superior a ter um papel fundamental na difusão cultural da região.

Francisco José Veiga, Francisco Carballo-Cruz e Linda Gonçalves Veiga, do Núcleo de Investigação em Políticas Económicas da Universidade do Minho, apresentam algumas recomendações para as políticas culturais, desta feita para as políticas culturais portuguesas para o período de 2014-2020 e com especial atenção a aspetos relacionados com a cooperação transnacional. As recomendações surgem na sequência de uma análise à dimensão cultural dos programas de Cooperação Territorial Europeia - um dos objetivos da política de coesão da União Europeia - e de um levantamento dos projetos na área da cultura e com parceiros portugueses que foram financiados por estes programas entre os anos de 2000 e de 2013. Os autores salientam que, não obstante os parcos recursos que até 2020 poderão ser captados por projetos culturais nos programas de Cooperação Cultural Europeia, o Governo e os diversos parceiros portugueses deverão adotar uma atitude proactiva e concertada na formação de parcerias, na escolha de temáticas e na dinamização de redes, nomeadamente através da promoção do alargamento ao espaço lusófono dos territórios enquadráveis nestes programas de cooperação cultural.

A dinamização de redes para as políticas culturais é, na realidade, uma recomendação que vem sendo sublinhada há várias décadas por vários investigadores e não se resume às ações de cooperação transnacional. Não obstante, Natália Azevedo do Instituto da Sociologia da Universidade do Porto, inspirada na sua dissertação de doutoramento de 2007 intitulada Políticas culturais, turismo e desenvolvimento local na Área Metropolitana do Porto - um estudo de caso, convoca os nove pontos que considera 
relevantes para uma discussão operacional sobre políticas culturais locais, para concluir que dois dos vetores principais dessas políticas ainda continuam, em Portugal e em 2014, atuais e por implementar: 1) a criação de uma rede municipal de equipamentos; e 2) a conceção e sustentabilidade de uma oferta cultural municipal.

Para Rui Matoso da Universidade Lusófona de Humanidades e Tecnologias, a solução para a resolução de problemas antigos das políticas culturais, nomeadamente das políticas culturais locais, passa pela implementação de práticas transformadoras que, no que se refere ao poder local, passam obrigatoriamente pela perceção da relação indissociável entre cidade, cultura e poder. Para o autor é também fundamental que se estabeleçam novas estruturas de relação de poder, nomeadamente através da reorganização e reposicionamento das instituições socioculturais existentes, que concorram para que se observe uma cessação do designado consenso operacional que favoreça o reconhecimento efetivo das necessidades e exigências culturais de um dado território.

Também no Brasil, pelo menos desde o ano de 1975, se sublinha a importância de articulação entre as políticas para o setor cultural, desta feita das políticas dos governos federal, estaduais e municipais; no entanto foi necessário esperar pelo Governo de Lula da Silva para se assistir à criação do Sistema Nacional de Cultura. O Sistema Nacional de Cultura é um programa criado com o objetivo de estabelecer, em conjunto com a sociedade civil, um sistema de políticas públicas específico para o setor cultural. A relevância do programa reside no facto de exigir a criação de mecanismos mínimos para o seu funcionamento nos estados e municípios, possibilitando, pelo menos teoricamente, algum grau de efetividade das políticas culturais independente do governo vigente. Não obstante a génese do programa se situar no Governo de Lula da Silva, a hipótese que Alexandre Barbalho da Universidade Estadual do Ceará no Brasil defende é a de que, ao contrário de outras frentes de atuação do Ministério da Cultura do Brasil, o processo de implantação deste programa ganhou um novo impulso no Governo Dilma Roussell.

As estruturas de relação de poder no âmbito das políticas culturais podem ser analisadas sob múltiplos pontos de vista. A proposta de Teresa Duarte Martinho e José Nuno Matos, do Instituto de Ciências Sociais da Universidade de Lisboa, é uma análise dos estatutos do Teatro Nacional de São Carlos em Portugal, com especial incidência para os que estiveram em vigor no período compreendido entre os anos de 1974 e de 2013. A visão apresentada permite perceber claramente que, no período analisado, os modelos de gestão adotados foram sendo influenciados pelas incertezas das políticas culturais públicas portuguesas, mas também por outros setores da sociedade civil. No 
artigo realça-se ainda que a instabilidade observada, a qual também pode ter sido provocada pela implementação de modelos não testados, pode ter contribuído para que, mais uma vez, problemas antigos diagnosticados em Portugal, como por exemplo a integração da instituição em circuitos internacionais, ainda não fosse uma realidade em 2014.

No final de uma viagem que pretende ser um contributo para uma discussão que se quer crítica e construtiva sobre as políticas culturais, apresenta-se uma reflexão filosófica sobre a importância do arquivo para a sobrevivência do discurso. $\mathrm{O}$ artigo de José Gomes Pinto e Carlos Pimenta, da Universidade Lusófona de Humanidades e Tecnologias, assume um simbolismo especial no final do $4^{0}$ número da Revista Lusófona em Estudos Culturais dedicado às Políticas Culturais. As discussões sobre as políticas culturais públicas e privadas, locais, regionais, nacionais e transnacionais, não são recentes e, não raras vezes, muitos dos problemas diagnosticados e muitas das soluções recorrentemente apresentadas estão nos arquivos e são arquivadas, mas os arquivos não são utilizados para iluminar o olhar, não são verdadeiramente tidos em conta para auxiliar o enquadramento e compreensão do real e, por isso, tornam inconsequentes muitos dos discursos produzidos, pois o que tem valor é dele destituído e os enunciados deixam de produzir sentido.

Moisés de Lemos Martins

Maria Manuel Baptista

Manuel Gama 